\title{
The role of brand image congruity in Iranian consumers' demand for auto parts
}

\author{
Naser Azad*, Maryam Safaei and Mahdieh Shahrabi Farahani
}

Department of Management and Accounting, South Branch, Islamic Azad University, Tehran, Iran

\begin{tabular}{|c|c|}
\hline CHRON I C L E & ABSTRACT \\
\hline $\begin{array}{l}\text { Article history: } \\
\text { Received December 28, } 2013 \\
\text { Accepted } 4 \text { May } 2014 \\
\text { Available online } \\
\text { May } 102014 \\
\text { Keywords: } \\
\text { Auto part } \\
\text { Consumer demand } \\
\text { Brand image }\end{array}$ & $\begin{array}{l}\text { One of the primary issues in handling demands for auto parts in the world is to build a mutual } \\
\text { trust between consumers and vendors. When people trust a brand, they purchase more easily } \\
\text { and it is possible to develop market. In Iran, there is a growing interest in demand for auto parts } \\
\text { and each year, tens of millions of auto parts are getting sold. This paper presents an empirical } \\
\text { investigation to detect the effects of brand image on demand for auto parts. Using a sample of } \\
202 \text { randomly selected people who buy/sell auto parts in city of Tehran, Iran, the study } \\
\text { determines three variables including brand strength, brand attributes and consumer trust through } \\
\text { the implementation of structural equation modeling. }\end{array}$ \\
\hline
\end{tabular}

\section{Introduction}

One of the primary issues in handling demands for auto parts in the world is to build a mutual trust between consumers and vendors. When people trust a brand, they purchase more easily and it is possible to develop market (Lassar, 1995; Liu, 2005). Measuring brand equity has been considered as an important issue among scholars (Aaker, 1996; Keller \& Lehmann, 2006; Keller et al., 2011). Brodie et al. (2009), for instance, investigated the effect of the service brand on the customer valueloyalty process by considering the traditional effect of brand image plus three additional effects that more fully reflect the broader service perspective including company image, employee trust, and company trust. They used some data from airline customers and reported a direct effect of all the characteristics of the brand on customers' perceptions of value. In addition brand image, company image and employee trust, in their survey, maintained a mediated effect on customer value through customers' perceptions of service quality. In addition, further analysis indicated that a service brand did not have a direct effect on customer loyalty but rather its effect was mediated through customer value.

\footnotetext{
*Corresponding author.

E-mail addresses: N_azad@azad.ac.ir (N. Azad) 
Heydari and Lotfizadeh (2014) examined the impact of the service brand on the customer valueloyalty process. The study includes the traditional impact of brand image plus three additional influences, which reflects the broader service perspective including company image, employee trust, and company trust. They reported a direct effect of some of the perspectives of the brand on customers' perceptions of value. In addition, the results indicated that brand image, organization image, trust to firm impact positively on quality of services. Finally, in their survey, brand image, organization image, quality of services and trust to firm impacted on customer's perspective where quality of services maintains the lowest impact and corporate image maintained the highest impact on customer's perspective.

$\mathrm{Hu}$ et al. (2012) investigated the role of brand image congruity in Chinese consumers' brand preference. The survey confirmed concerning functional image congruity and revealed that symbolic image congruity had a negative effect on Chinese consumers' brand preference when a brand's perceived symbolic image was higher than consumers' ideal expectations (i.e. upward incongruity), and brand familiarity did not moderate the role of symbolic image congruity in Chinese consumers' brand preference.

Kim et al. (2008) investigated different factors influencing on brand equity in health care industry. They identified five factors, which impact the creation of brand equity through successful customer relationships including trust, customer satisfaction, relationship commitment, brand loyalty, and brand awareness. An empirical investigation of the relationships among these factors recommended that hospitals could be successful in building image and positive brand equity if they could manage their customer relationships well.

Low et al. (2000) examined empirically a conceptualization of brand associations, which consists of three dimensions; namely brand image, brand attitude and perceived quality. A better understanding of brand associations was requested to facilitate further theoretical development and practical measurement of the construct. They performed three studies to examine a protocol for developing product category specific measures of brand image; to understand the dimensionality of the brand associations construct; and finally to explore whether the degree of dimensionality of brand associations changes depending upon a brand's familiarity. They confirmed the efficacy of the brand image protocol and reported that brand associations differed across brands and product categories. They also supported the conclusion that brand associations for various products should be measured using various items. Michel and Rieunier (2012) investigated the effect of nonprofit brand image and typicality on giving behaviors and created a scale to measure the brand image of charities by investigating four dimensions of nonprofit brands emerge in the new scale including usefulness, efficiency, affect and dynamism.

\section{The proposed study}

In this paper, we present an empirical investigation to detect the effects of brand image on demand for auto parts. The population of the survey includes all potential people who buy/sell auto parts in Iran. Therefore, the sample size is calculated as follows,

$$
N=Z_{\alpha / 2}^{2} \frac{p \times q}{e^{2}},
$$

where $N$ is the sample size, $p=1-q$ represents the probability, $z_{\alpha / 2}$ is CDF of normal distribution and finally $\varepsilon$ is the error term. For our study we assume $p=0.5, z_{\alpha / 2}=1.96$ and $e=0.05$, the number of sample size is calculated as $N=198$. The study designs a questionnaire in Likert scale and first distributes ten questionnaires among some experts and tries to validates the questionnaire. Cronbach alpha has been calculated as 0.823 , which is well above the minimum acceptable level. Therefore, we may use the questionnaire for the proposed study and 202 questionnaires were distributed among some randomly selected people. Fig. 1 demonstrates personal characteristics of the participants. 


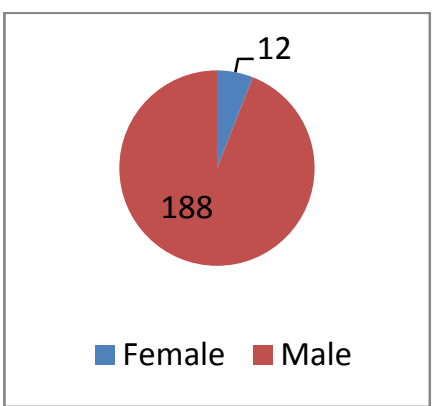

Gender

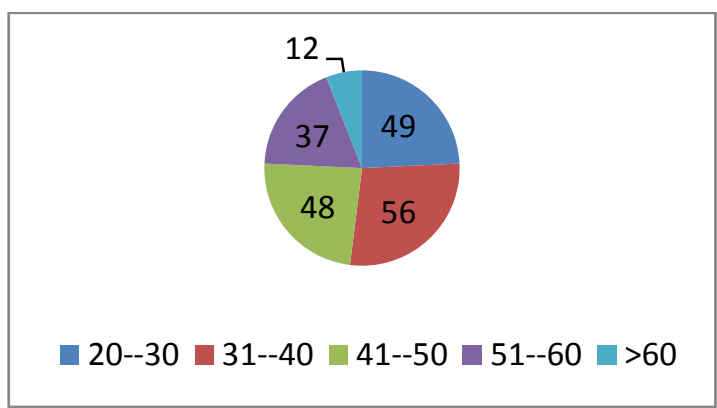

Age

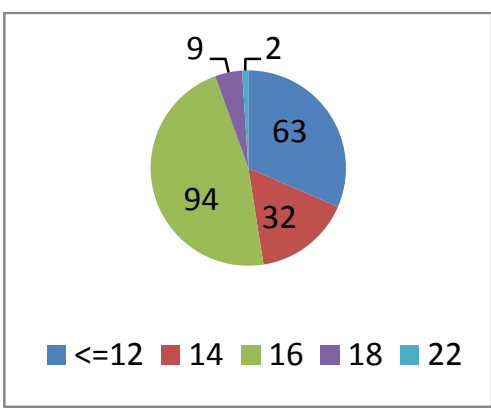

Years of education

Fig. 1. Personal characteristics of the participants

As we can observe from the results of Fig. 1, most participants in our survey were male and middle age and surprisingly over half of them had some university educations. During the study, we initially extracted 25 variables and then summarized them into 16 variables. Table 1 shows the title of these items.

\section{Table 1}

The summary of 16 variables of the survey

\begin{tabular}{llll}
\hline Item & Description & Item & Description \\
\hline 1 & Market share & 9 & Product characteristics \\
2 & Brand credibility & 10 & Positioning strategies with successful brands \\
3 & Brand identity & 11 & Brand differentiation \\
4 & Consumer perception & 12 & Consumer understanding \\
5 & Price & 13 & Advertisement \\
6 & Retaining consumer's believes & 14 & Packaging \\
7 & Consumer's level of confidence & 15 & Color used in products \\
8 & Brand power & 16 & Brand logo \\
\hline
\end{tabular}

The proposed study considers the following four hypotheses,

1. Brand image influences positively on demand for auto part.

2. Brand power influences positively on demand for auto part.

3. Brand characteristics influence positively on demand for auto part.

4. Consumer market influences positively on demand for auto part.

The study uses structural equation modeling to investigate the effects of four mentioned variables on demand for auto parts. In order to find the efficient number of components we have applied Scree plot and Fig. 2 shows details of our findings.

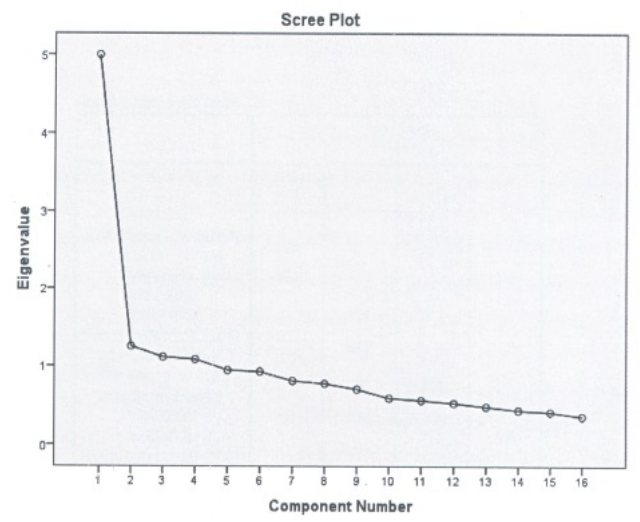

Fig. 2. The summary of Scree plot 
Based on the results of Fig. 2, we may extract three important factors including brand strength, brand attributes and consumer trust through the implementation of structural equation modeling. Next, we present details of our findings. Fig. 3 shows details of the results of structural equation modeling.

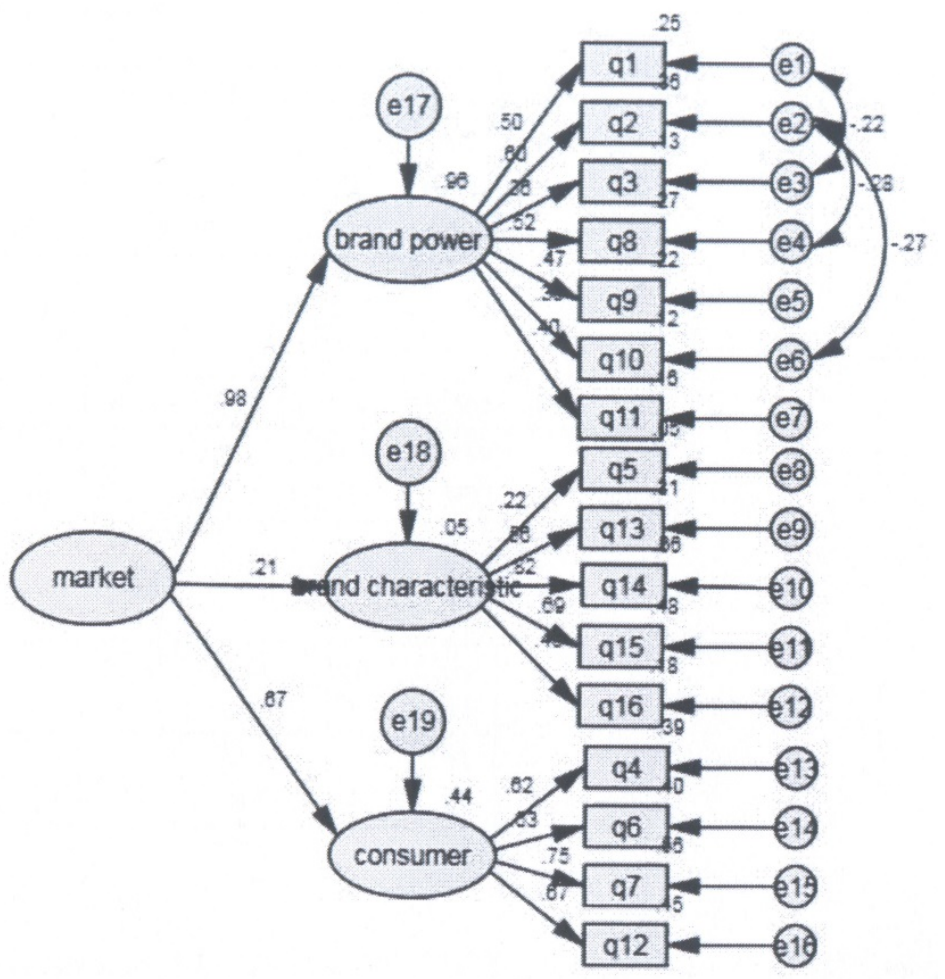

Fig. 3. The results of structural equation modeling

\section{The results}

As explained, there are three factors, which influence on consumer demand. The first component is associated with brand power and Table 2 summarizes the results of our findings.

\section{Table 2}

The summary of various components associated with brand power

\begin{tabular}{|c|c|c|c|c|}
\hline Item & Factor loading & Eigen value & Variance & \%Accumulated \\
\hline Brand characteristics & 0.679 & 2.730 & 16.892 & 16.892 \\
\hline Market share & 0.670 & & & \\
\hline Brand power & 0.659 & & & \\
\hline Brand credibility & 0.628 & & & \\
\hline Positioning strategies with successful brands & 0.463 & & & \\
\hline Brand differentiation & 0.466 & & & \\
\hline Product characteristics & 0.398 & & & \\
\hline
\end{tabular}

As we can observe from the results of Table 1, Brand characteristics is number one priority followed by market share, brand power and brand credibility. Next component is called brand characteristics with five sub-components summarized in Table 3 as follows,

\section{Table 3}

The summary of various components associated with brand characteristics

\begin{tabular}{lcccc}
\hline Item & Factor loading & Eigen value & Variance & \%Accumulated \\
\hline Color & 0.748 & 2.203 & 13.766 & 30.658 \\
Logo & 0.728 & & & \\
Advertisement & 0.487 & & & \\
Packaging & 0.642 & & & \\
Price & 0.394 & & \\
\hline
\end{tabular}


According to the results of Table 3, color used in brand is number one priority followed by logo and packaging. In addition, advertisement and price are other important issues associated with brand characteristics. Consumer believes is the last component of our survey and Table 4 shows details of our findings.

\section{Table 4}

The summary of various components associated with consumer believes

\begin{tabular}{lcccc}
\hline Item & Factor loading & Eigen value & Variance & \%Accumulated \\
\hline Level of consumer's confidence & 0.677 & 2.047 & 12.793 & 43.451 \\
Retaining consumer's believes & 0.642 & & & \\
Consumer perception & 0.346 & & & \\
Consumer's understanding & 0.719 & & & \\
\hline
\end{tabular}

Based on the results of Table 4, consumer's understanding is number one priority followed by level of consumer's confidence, retaining consumer's believes and consumer perception.

\section{Conclusion}

In this paper, we have presented an empirical investigation to study the effects of various factors influencing on consumer's demand for auto parts in Iran. The study has implemented structural equation modeling and detected three factors, which influence the most on consumer's demand in Iranian auto industry. In terms of brand power, brand characteristics is number one priority followed by market share, brand power and brand credibility. Brand characteristics is another important factor where color used in brand is number one priority followed by logo and packaging. In addition, advertisement and price are other important issues associated with brand characteristics. Consumer believes is the last item where consumer's understanding is number one priority followed by level of consumer's confidence, retaining consumer's believes and consumer perception. In summary Table 5 shows details of our testing four hypotheses of the survey.

\section{Table 5}

The summary of testing four hypotheses

\begin{tabular}{lcccccccccc}
\hline Parameter & SE & SE_SE & Mean & Bias & SE_Bias & Estimate & Lower & Upper & P \\
\hline Brand power $\rightarrow$ consumer demand & 0.000 & 0.000 & 1.000 & 0.000 & 0.000 & 1.000 & 1.000 & 1.000 & $\ldots$. & 0.000 \\
Brand characteristics $\rightarrow$ consumer demand & 0.065 & 0.003 & 0.087 & 0.006 & 0.005 & 0.081 & 0.016 & 0.232 & 0.018 \\
Consumer believes $\rightarrow$ consumer demand & 0.282 & 0.014 & 0.866 & 0.063 & 0.020 & 0.802 & 0.447 & 1.207 & 0.025 \\
\hline
\end{tabular}

\section{Acknowledgement}

The authors would like to thank the anonymous referees for constrictive comments on earlier version of this paper.

\section{References}

Aaker, D. A. (1996). Measuring brand equity across products and markets. California Management Review, 38(3), 102-120.

Brodie, R. J., Whittome, J. R., \& Brush, G. J. (2009). Investigating the service brand: a customer value perspective. Journal of Business Research, 62(3), 345-355.

Heydari, L., \& Lotfizadeh, F. (2014). Investigating the service brand: A customer value perspective. Management Science Letters, 4(4), 613-616.

$\mathrm{Hu}$, J., Liu, X., Wang, S., \& Yang, Z. (2012). The role of brand image congruity in Chinese consumers' brand preference. Journal of Product \& Brand Management, 21(1), 26-34.

Keller, K. L., \& Lehmann, D. R. (2006). Brands and branding: Research findings and future priorities. Marketing Science, 25(6), 740-759.

Keller, K. L., Parameswaran, M. G., \& Jacob, I. (2011). Strategic brand management: Building, measuring, and managing brand equity. Pearson Education India. 
Kim, K. H., Kim, K. S., Kim, D. Y., Kim, J. H., \& Kang, S. H. (2008). Brand equity in hospital marketing. Journal of business research, 61(1), 75-82.

Lassar, W., Mittal, B., \& Sharma, A. (1995). Measuring customer-based brand equity. Journal of consumer marketing, 12(4), 11-19.

Liu, X. (2005). Research on decision rule and scheme evaluation of brand strategy. China-USA Business Review, 4(8), 22-26.

Low, G. S., \& Lamb Jr, C. W. (2000). The measurement and dimensionality of brand associations. Journal of Product \& Brand Management, 9(6), 350-370.

Michel, G., \& Rieunier, S. (2012). Nonprofit brand image and typicality influences on charitable giving. Journal of Business Research, 65(5), 701-707. 